\title{
К ПРОБЛЕМАМ ОЦЕНКИ ЭФФЕКТИВНОСТИ ПОДРАЗДЕЛЕНИЙ ВЫСШЕГО УЧЕБНОГО ЗАВЕДЕНИЯ НА ОСНОВЕ СИСТЕМЫ СБАЛАНСИРОВАННЫХ ПОКАЗАТЕЛЕЙ
}

\author{
(c) 2018 Николаева Елена Анатольевна \\ кандидат социологических наук, доцент \\ кафедра иностранных языков № 3 \\ Российский экономический университет имени Г.В. Плеханова \\ 115093, г. Москва, Стремянный пер., 36 \\ E-mail:yoltash82@mail.ru \\ (c) 2018 Агибалова Елена Леонидовна \\ кандидат филосовских наук, доцент \\ заведующая кафедрой кафедра иностранных языков № 3 \\ Российский экономический университет имени Г.В. Плеханова \\ 115093, г. Москва, Стремянный пер., 36 \\ E-mail:kafmkk@mail.ru \\ (c) 2018 Каржанова Наталья Викторовна \\ кандидат филосовских наук, доцент \\ кафедра иностранных языков № 3 \\ Российский экономический университет имени Г. В. Плеханова \\ 115093, г. Москва, Стремянный пер., 36 \\ E-mail:kafmkk@mail.ru \\ (c) 2018 Тимчишена Елена Александровна \\ старший преподаватель \\ кафедра иностранных языков № 3 \\ Российский экономический университет имени Г.В. Плеханова \\ 115093, г. Москва, Стремянный пер., 36 \\ E-mail:kafmkk@mail.ru
}

Вопрос, затрагиваемый в статье авторов, является на сегодняшний день весьма актуальным, как для локального образовательного учреждения, так и для системы высшего профессионального образования в целом. Объектом исследования выступили подразделения высшего учебного заведения, а предметом - проблемы оценки эффективности их функционирования. Теоретико-методологическое значение статьи заключается в формировании единого подхода к пониманию накопившихся проблем в оценке эффективности подразделений высшего учебного заведения, а практическое - в обозначении ключевых направлений их решения.

Ключевые слова: высшее учебное заведение, проблемы, подразделение, сложности, система сбалансированных показателей, оценка эффективности, материальное вознаграждение, экономический аспект обучения.

Высшие учебные заведения являются важнейшим звеном системы профессионального образования любой экономически развитой страны [5], так как именно здесь кадровая составляющая общества обретаем целостное содержание, проецируемое на дальнейшее практическое использование.

Процесс эффективного управления высшим учебным заведением невозможен без комплекс- ной системы оценки эффективности его функционирования [1, с.59], основанной на применении широкого спектра показателей, отражающих специфику его деятельности в профильном направлении. При этом совокупность показателей, должна отражать не только интегральную результативность работы высшего учебного заведения [2, с.98], как такового, но и эффективность работы его подразделений [6, с. 952]. 
Исходя из того, что количество подразделений современного высшего учебного заведения федерального уровня насчитывает более ста локальных единиц [4], совокупность показателей эффективности их работы требует глобальной и методически обоснованной систематизации [7, c.11].

По данным консалтинговой фирмы Ernst\&Young на начало 2018 года в Российской Федерации более 50\% высших учебных заведений для систематизации показателей оценки эффективности своей деятельности, в том числе по работе подразделений, в том или ином виде использовали систему сбалансированных показателей [3]. Ниже на рисунке 1 приведена градация использования системы сбалансированных показателей в оценке эффективности работы высших учебных заведений Российской Федерации (ВУЗ) на начало 2018 года.

Из рисунка 1 можно увидеть, что из 52,72\% высших учебных заведений Российской Федерации, использующих систему сбалансированных показателей в оценке эффективности своей ра- боты лишь 9,35\% освоили методику в комплексе (методика применяется во всех без исключения подразделениях). Порядка 15,98\% высших учебных заведений используют систему локально (в работе одного и более подразделений), в то время как подавляющее большинство (чуть более 27\%) анализируемых высших учебных заведений применяет лишь элементы системы сбалансированных показателей в некоторых из своих подразделений. При этом оставшаяся часть совокупности $(47,21 \%$ высших учебных заведений) не применяет в явном виде систему сбалансированных показателей вообще.

Столь низкая проницаемость внедрения системы сбалансированных показателей в высших учебных заведениях объясняется наличием целого ряда значительных проблем, затрагивающих отдельные параметры функционирования конкретного объекта.

Изучив работу ряда высших учебных заведений г. Москвы (в т.ч. ФГБОУ ВО «Российский экономический университет им. Г.В. Плеханова») в 2016-2018 годах, использующих для оценки эф-

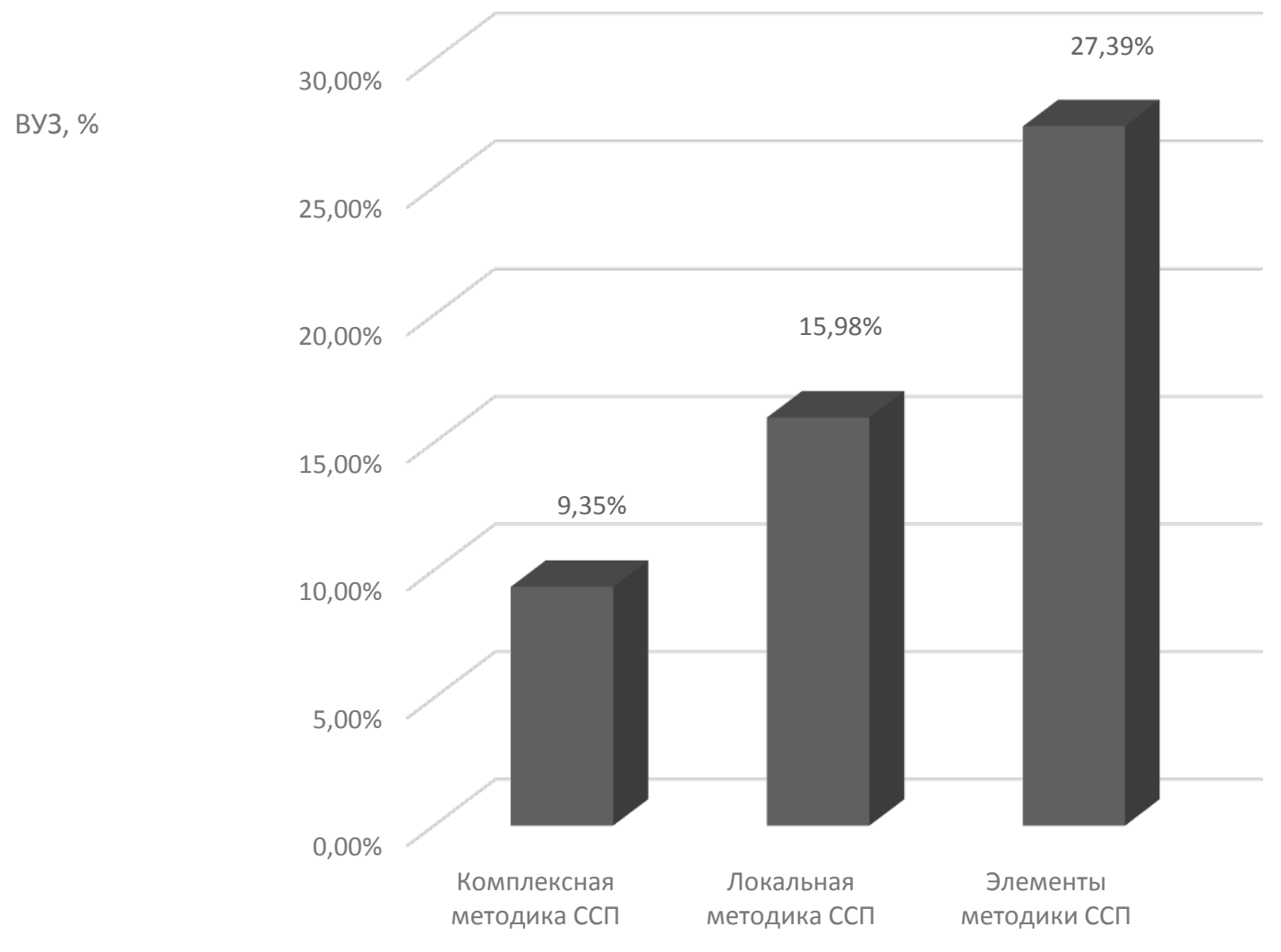

Градация

Puc. 1. Градация использования системы сбалансированных показателей в оценке эффективности работы высших учебных заведений Российской Федерации на начало 2018 года 
фективности функционирования большинства своих подразделений (не менее 50\% подразделений от их совокупного объема) были выявлены и систематизированы проблемы, представленные на рисунке 2. Каждой проблеме экспертным путем был присвоен персональный уровень значимости (в совокупности не более $100 \%$ для всех пяти проблем), отражающий относительное положение проблемы в анализируемой совокупности.

На основе данных рисунка 2 можно сделать следующие выводы:

- наиболее значимой из анализируемого перечня проблем (уровень значимости порядка 32,19\% из 100 возможных) является проблема, связанная с недостаточным учетом специфики деятельности подразделений высшего учебного заведения. Так, например, показатели эффективности деятельности кафедр одной проекции формируются безотносительно преподаваемых ими дисциплин, количества студентов и квалификации преподавательского состава в отдельных узко специализированных вопросах;

- вторая не менее значимая проблема касается длительности периода обработки первичных данных (уровень значимости порядка 23,15\% из 100 возможных). Суть данной проблемы состоит в том, что для расчета многих показателей эффективности подразделений высшего учебного заведения в рамках системы сбалансированных показателей необходимо проводить дополнительные расчеты и вычисления (особенно это касается нефинансовых относительных показателей, затрагивающих, например,

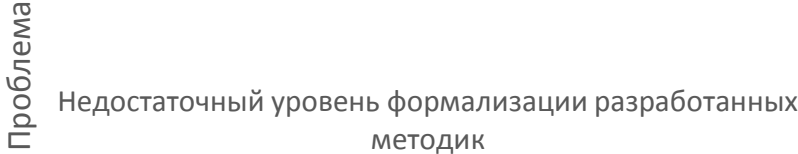

Значительная демотивация исполняющих сотрудников низового звена

Длительный период обработки первичных данных

Низкая практическая проработанность применения методик расчета показаталей

Недостаточный учет специфики деятельности подразделения

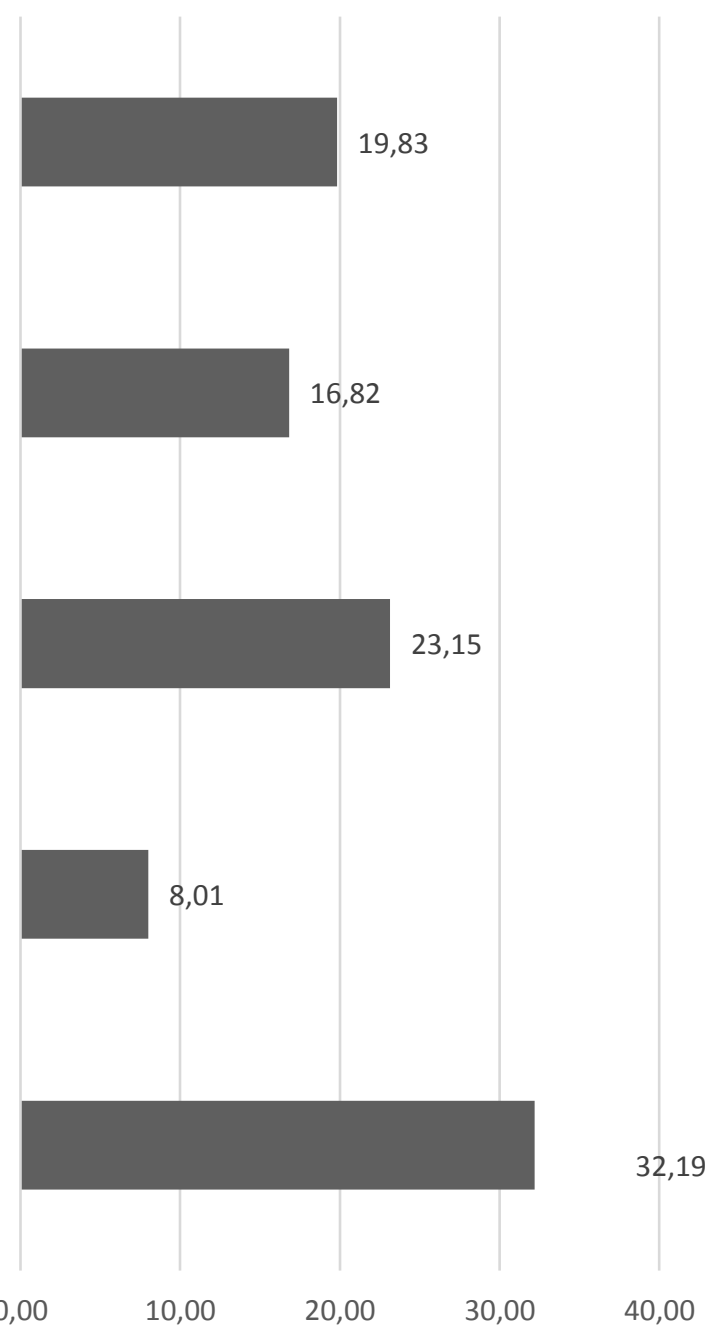

Значимость, \%

Puc. 2. Проблемы оценки эффективности подразделений высших учебных заведений, применяющих систему сбалансированных показателей 
качество учебного процесса или разработанной документации), что связано с существенными затратами времени, и соответственно, с превышением фактических сроков обработки первичных данных над плановыми;

- следующей по значимости проблемой является недостаточный уровень формализации разработанных методик (уровень значимости порядка 19,83\% из 100 возможных). В рамках данной проблемы поясним, что счетная карта стратегического плана высшего учебного заведения, построенная по методике системы сбалансированных показателей, зачастую не содержит описание процесса измерения локальных показателей второго и третьего причинно-следственного порядка для конкретного подразделения (необходимые методики не отражены в положениях кафедр, должностных инструкциях сотрудников и других формализующих документах), ввиду чего, их руководители вынуждены прибегать к единоличному и зачастую, не достаточно объективному трактованию тех или иных событий и фактов. Также здесь возникает ряд сложностей с контролем за исполнением процесса стратегического планирования;

- чуть менее важная проблема (уровень значимости порядка 16,82\% из 100 возможных) затрагивает существенную демотивацию сотрудников низового звена. Например, многие штатные единицы, не имеющие ученой степени (ассистенты, лаборанты, секретари и т.д.) изначально находятся в менее привилегированном с финансовой точки зрения положении, относительно остепененных сотрудников, что существенным образом снижает уровень их мотивации к исполнению своих обязанностей в сфере заполнения документации, относящейся к прямому и косвенному анализу показателей эффективности подразделения высшего учебного заведения. Ввиду этого данная категория персонала начинает абсолютно не обоснованно эмулировать значения некоторых важных показателей деятельности подразделения или умышленно занижает, или завышает их результаты. Данные действия весьма негативным образом отражаются на объективности оценок показателей эффективности деятельности как подразделения в частности, так и высшего учебного заведения в целом;

- завершает перечень проблема низкой практической проработанности применения методик расчета показателей (уровень значимости порядка 8,01\% из 100 возможных). Суть данной проблемы состоит в недостаточной обоснованности контрольных значений показателей эффективности подразделений высшего учебного заведения, которые формируются не путем анализа текущей внутренней и внешне ситуации, а директивно вписываются в стратегический план руководящим составом. Например, объем плановой научно-исследовательской работы студентов не может носить безотносительный характер для технических и гуманитарных подразделений высшего учебного заведения, ввиду существенных различий в количестве и составе обучающихся студентов в анализируемый период времени. Аналогичная ситуация, зачастую, имеет место с показателями планового объема хозяйственно-договорных работ, приходящихся на различные подразделения высшего учебного заведения.

Для устранения вышеназванных проблем в сфере оценки эффективности подразделений высшего учебного заведения, на наш взгляд, целесообразно инициировать следующий перечень мероприятий:

- более обоснованно и в формализованном виде учитывать специфику каждого подразделения высшего учебного заведения и лишь после этого формировать локальный элемент системы сбалансированных показателей по всем проекциям (персонал, финансы, процессы, технологии);

- сократить период анализа сформированных данных за счет унификации вычисления всех без исключения показателей деятельности подразделения высшего учебного заведения в рамках всех проекций;

- максимально детализировать счетную карту стратегического плана высшего учебного заведения, построенную по методике системы сбалансированных показателей, которая будет содержать детальное и поэтапное описание процесса измерения локальных показателей второго и третьего причинно-следственного порядка для конкретного подразделения;

- повысить уровень финансовой мотивации сотрудников низового звена высшего учебного заведения, например, путем их квартального и годового премирования за эффективное выполнение своих должностных обязанностей в сфере заполнения первичной документации (также возможно рассмотреть вариант возмездного участия данной категории персонала в реализа- 
ции грантов и иных доходных проектов высшего учебного заведения);

- значительно повысить уровень практической проработанности применения методик расчета показателей с ежегодным или ежеквартальным пересмотром контрольных значений показателей эффективности каждого конкретного подразделения высшего учебного заведения с учетом влияния комплекса актуальных внешних и внутренних факторов.

Таким образом, можно сделать вывод, что многие высшие заведения в Российской Федерации при разработке планов стратегического развития ориентируются на популярную во всем мире систему сбалансированных показателей Д. Нортона и Р. Каплана.
Процесс оценки эффективности высших учебных заведений и их подразделений в Российской Федерации не является оптимальным и связан со значительным перечнем проблем, затрагивающим, в основном, методические и информационные аспекты анализируемого процесса.

Для разрешения обозначенного перечня проблем необходимо в значительной мере переосмыслить роль подразделений высших учебных заведений в анализируемом процессе, сделав акцент на выделении, детальном анализе и непрерывном мониторинге их специфических особенностей в совокупности с факторами внешней и внутренней среды в заданный период времени.

\section{Библиографический список}

1. Сидорова Н.А. Высшее образование как элемент инновационной социально ориентированной экономики / Н.А. Сидорова // Вопросы экономики и права. 2012. № 5. С. 58-61.

2. Туктарова П.А. Система сбалансированных показателей в антикризисном менеджменте / П.А. Туктарова // Вопросы экономики и права. 2016. № 3. С. 95-98.

3. Компания Ernst\&Young [Электронный ресурс]: Внутренние аналитические материалы - Официальный сайт компании Ernst\&Young, 2018. - Режим доступа: http:// www.ey.com

4. Рейтинговое агентство Эксперт-РА [Электронный ресурс]: Аналитические матери-алы.- Официальный сайт Рейтингового агентства «Эксперт-РА», 2018.- Режим доступа: http://raexpert.ru/

5. Al-Hosaini, F.F. and S. Sofian, 2015. A review of balanced scorecard framework in higher education institution (HEIs). International Review of Management and Marketing, 5(1): 26-35

6. Fooladvand, M., M.H. Yarmohammadian and S. Shahtalebi, 2015. The application strategic planning and balance scorecard modelling in enhance of higher education. Procedia-Social and Behavioral Sciences, 186: 950-954.

7. Sudaryo, Y., 2015. Performance of universities with a strategic map balanced scorecard approach: Study at 6 high school of economics in Bandung city. Sosiohumaniora, 17(1): 1-12. 